\title{
COMPARAÇÃO DAS PELES DE TILÁPIA DO NILO, PACU E TAMBAQUI:HISTOLOGIA, COMPOSIÇÃO E RESISTÊNCIA
}

\author{
COMPARATIVE ANALYSIS OF THE SKINS OF NILE TILAPIA, PACU AND TAMBAQUI: \\ HISTOLOGY, COMPOSITION AND RESISTANCE
}

\author{
Franco, M.L.R.S. ${ }^{1}$; Franco, N.P. ${ }^{2}$; Gasparino, E. ${ }^{1}$; Dorado, D.M. ${ }^{3}$; Prado, M. ${ }^{2}$ \\ e Vesco, A.P.D. ${ }^{2 *}$
}

\begin{abstract}
'Departamento de Zootecnia. Universidade Estadual de Maringá. Maringá-PR. Brasil.mlrsouza@uem.br ${ }^{2}$ Pós-graduação em Zootecnia. Universidade Estadual de Maringá. Maringá-PR. Brasil. *apaulavesco@gmail.com

${ }^{3}$ Centro de Ciências Biológicas, Agrárias e Saúde. Universidade pra o Desenvolvimento do Estado e da Região do Pantanal (UNDERP). Brasil. douradod@uol.com.br
\end{abstract}

\section{Palavras chave adicionais}

Testes de resistência. Testes físico-químicos.

\section{RESUMO}

O objetivo deste trabalho foi comparar as peles de tilápia (Oreochromis niloticus), pacu (Piaractus mesopotamicus) e tambaqui (Colossoma macroporum) quanto à histologia, composição centesimal, características físicoquímica e físico-mecânica. Para tanto foram utilizados $10 \mathrm{~kg}$ de peles de cada espécie. Todas as peles seguiram a mesma metodologia de curtimento, sendo todas processadas em fulão. Foram realizadas análises histológicas e de composição nas peles in natura, e após o curtimento foram utilizados 20 couros de cada espécie para obtenção dos corpos-de-prova de cada tratamento para análises físico-química e físico-mecânica. A pele de tilápia do Nilo apresentou lamélulas maiores que as demais espécies analisadas, entretanto, a camada mais profunda da derme desta espécie apresenta feixes de fibras colágenas mais finas no sentido transversal a superfície da pele, enquanto nas peles de pacu e tambaqui observouse fibras colágenas mais espessas no sentido longitudinal e grossos feixes de fibras colágenas no sentido transversal a superfície da pele. A pele de tilápia do Nilo apresentou maior teor de umidade $(67,14 \%)$, lipídeos (1,96 \%) e cinzas (1,82\%), entretanto a pele dessa espécie foi a que apresentou menor teor de proteína bruta $(29,08$ $\%)$. Maior teor de proteína bruta foi encontrado nas peles de tambaquis $(35,70 \%)$. Os couros de

\section{AdDitiONAL KEYWORDS}

Physical-chemical tests. Tests of resistance.

tilápia do Nilo apresentaram menor espessura $(0,68 \mathrm{~mm})$, resistência à tração $\left(11,86 \mathrm{~N} / \mathrm{mm}^{2}\right)$, rasgamento progressivo $(40,18 \mathrm{~N} / \mathrm{mm})$, menor elasticidade $(52,63 \%)$ e menor força máxima $(81,06 \%)$ comparada aos couros de pacu e tambaqui. Sendo o couro de tambaqui, o de maior espessura $(0,89 \mathrm{~mm})$ e resistência para as variáveis analisadas (tração $=29,49 \mathrm{~N} / \mathrm{mm}^{2}$, rasgamento progressivo $=80,01 \mathrm{~N} / \mathrm{mm}$ e força máxima $=224,25$ ). Os couros de tilápia são menos resistentes que os de pacu e tambaqui; os couros de tambaqui, poderiam ser destinados à confecção de vestuários, e os couros das três espécies apresentam a espessura dentro do recomendado para confecção de luvas e vestimentas.

\section{SUMMARY}

The aim of this work was to compare the tilapia (Oreochromis niloticus), pacu (Piaractus mesopotamicus) and tambaqui (Colossoma macroporum) skins on the histology, composition, physico-chemical and physico-mechanical features. Therefore, $10 \mathrm{~kg}$ of skins of each species were used. All skins have followed the same methodology for tanning, all processed in tannery machine. Histological and composition analysis were conducted in fresh skin, and 20 leather of each species were used after tanning for physical- 
chemical and physico-mechanical analysis. The skin of Nile tilapia showed lamellulae larger than the other species examined, however, the deeper layer of the dermis of this species shows collagen fibers thinner in the transverse direction to the skin surface. The Nile tilapia skin had a higher humidity $(67.14 \%)$, lipid (1.96\%) and ash contents (1.82 $\%)$, though the skin of this species showed the lowest level of crude protein (29.08\%). A higher content of crude protein was found in tambaqui skins $(35.70 \%)$. The Nile tilapia leather showed lower thickness $(0.68 \mathrm{~mm})$, tensile strength $(11.86$ $\mathrm{N} / \mathrm{mm}^{2}$ ), progressive tearing $(40.18 \mathrm{~N} / \mathrm{mm})$, elasticity $(52.63 \%)$ and lower maximum strength $(81.06 \%)$ compared to pacu and tambaqui leathers. It was observed that the tambaqui leather was the thickest $(0.89 \mathrm{~mm})$ and most resistante for the measured variables (tensile strength $=29.49 \mathrm{~N} /$ $\mathrm{mm}^{2}$, progressive tearing $=80.01 \mathrm{~N} / \mathrm{mm}$ and maximum strength $=224.25$ ). Tilapia leathers are less resistant than tambaqui and pacu leathers and the tambaqui leather could be destined for the manufacture of clothing, and the leathers of the three species have thickness within recommended for gloves and clothing manufacture.

\section{INTRODUÇÃO}

A piscicultura é uma das novas atividades do meio rural, que vem atraindo muitos ex-produtores e novos empresários agrícolas, isto está ocorrendo, devido às altas taxas de retorno e de lucratividade, quando comparado às outras opções de investimentos (Martins et al., 2001). A produção mundial de peixes apresenta contínuo crescimento. Este aumento tem sido obtido graças ao crescimento da aquicultura que vem se mostrando a melhor alternativa para suprir a estagnação da produção pesqueira de captura.

Dentro da atividade de processamento, a tilápia (Oreochromis niloticus) foi umas das espécies que melhor se adaptou a nova inovação dentro da piscicultura. A tilápia apresenta um filé de excelente qualidade, de ótima aceitação, sabor suave e característico da espécie.

O pacu (Piractus mesopotamicus), originário da Bacia do Prata, onde é conhecido como pacu-caranha ou caranha, é um peixe de grande porte, com o corpo robusto e arredondado, apresentando dorso cinza-escuro e o ventre amarelo-dourado (Vaz et al., 2000). Esta espécie é uma das mais procuradas pelos pescadores amadores e profissionais, apresentando uma carne saborosa que possui particularidades na culinária quanto à maneira do seu preparo. Essas particularidades geram subprodutos que podem ser processados e aproveitados de maneira sustentável, principalmente com o aproveitamento da pele.

O tambaqui (Colossoma macroporum)é uma espécie nativa da bacia do Amazonas, apresenta grande valor econômico e é muito consumido na região Norte e Nordeste do país. Com a implantação de frigoríficos, principalmente em Manaus e cidades circunvizinhas, a pesca empresarial está emergindo para atender os mercados nacionais e internacionais desta espécie.

O mercado consumidor está buscando novas formas de apresentação do pescado, de forma que facilite, principalmente, o seu preparo. Dentre as três espécies analisadas, o pacu e o tambaqui têm como opção a realização de diferentes cortes comerciais que possibilitam atender esta demanda. Para tanto, a pele deve ser removida, sendo esta utilizada como um resíduo de qualidade para o processo de curtimento e aplicação na indústria de confecção de artefatos em geral ou mesmo de calçados e vestuário.

Quanto à tilápia, já é uma espécie que vem sendo utilizada para filetagem e, com isso, a quantidade de resíduos gerada com o processamento é extremamente elevada, chegando a 60 ou $70 \%$ do peso corporal do peixe. Portanto, torna-se necessário a busca de alternativas para aproveitamento desses resíduos das diferentes espécies exploradas comercialmente.

Dentre os resíduos, a pele corresponde de 4,5 a $10 \%$ do peso corporal. Essa variação deve-se a espécie de peixe e forma de sua retirada (método de filetagem) (Souza, 2008). No entanto, independente da espécie do 


\section{ANÁLISE COMPARATIVA DAS PELES DE TILÁPIA DO NILO, PACU E TAMBAQUI}

peixe, a pele pode ser beneficiada, e após o curtimento, sua resistência e seu desenho de flor (formado pelas lamélulas de proteção e inserção de escamas) resulta em uma matéria-prima de qualidade e de aspecto peculiar inimitável, de acordo com cada espécie.

Com o intuito de aproveitamento das peles geradas do processamento da tilápia do Nilo, a espécie mais cultivada no mundo, do tambaqui e pacu, espécies nativas muito produzidas em suas respectivas regiões, o objetivo do experimento foi comparar as peles dessas três espécies quanto à histologia e composição centesimal e após o curtimento as características físico-química e físico-mecânica.

\section{MATERIALE MÉTODOS}

O experimento foi realizado no Laboratório de Processamento de Peles de Peixes e demais Espécies de Pequeno e Médio Porte, da Universidade Estadual de Maringá, localizado na Fazenda Experimental de Iguatemi (FEI).

\section{ANIMAIS EXPERIMENTAISEPROCESSAMENTO}

Foram utilizados $10 \mathrm{~kg}$ de peles de tilápia do Nilo (Oreochromis niloticus), provenientes de pesqueiro de Umuarama, $10 \mathrm{~kg}$ de peles de pacu (Piaractus mesopotamicus) e $10 \mathrm{~kg}$ de peles de tambaqui (Colossoma macroporum) vindos de Sinópe (Mato Grasso). Todas as três espécies provenientes de cultivo de tanque escavados, recebendo ração comercial variando de 36 a $28 \%$ de proteína bruta, respectivamente de juvenis até o peso de abate. O peso médio de abate dos peixes foi de $800 \mathrm{~g}$ para tilápia, 1500 g para pacu e 1500 g para tambaqui.

Os peixes foram insensibilizados por choque térmico (caixas isotérmicas com gelo moído e água, 1:1), e em seguida realizada a sangria. Após o abate dos peixes, foram retirados os filés e destes, com o auxílio de uma faca, removidas as peles. Em seguida, foram submetidas ao congelamento até o momento do curtimento. Todas as peles seguiram a mesma metodologia, sendo processadas em um único equipamento, o fulão (tambor utilizado para adição das peles e soluções para o curtimento das peles).

Para iniciar o processamento, as peles foram descongeladas à temperatura ambiente, pesadas, descarnadas e novamente pesadas antes do processo de curtimento.

No processo de curtimento, as peles foram submetidas a uma série de etapas, seguidas de acordo com Hoinacki (1989) e Souza et al. (2004). As etapas foram o remolho, descarne, caleiro (3\% de sulfeto de sódio e $3 \%$ de cal), desencalagem, desengraxe, purga, píquel, curtimento (6\% de sais de cromo), neutralização, recurtimento ( $2 \%$ de tanino vegetal e $2 \%$ de tanino sintético), tingimento, engraxe (9\% de óleos), secagem e amaciamento.

\section{ANÁLISE HISTOLÓGICA DAS PELES}

Foram retiradas amostras da região dorsal das três espécies de peixes para a análise histológica. As amostras foram fixadas em formol $10 \%$ e incluídas em parafina. As amostras foram cortadas com aproximadamente $5 \mu \mathrm{m}$ de espessura e coradas pela técnica de hematoxilina-eosina (HE) para descrever a histologia geral da pele. Os cortes histológicos foram analisados pela microscopia de luz, selecionados e fotomicrografados em fotomicroscópio Axiox Kop Zeiss.

\section{COMPOSIÇÃO}

Amostras de peles in natura das três espécies de peixes $(n=10)$ foram embaladas em sacos plásticos, identificados e congelados $\left( \pm 18{ }^{\circ} \mathrm{C}\right)$, e após descongelamento foram trituradas em multiprocessador. Alíquotas desse material foram utilizadas para as determinações de composição. Os teores de umidade e cinzas foram determinados conforme descrito em AOAC (1995). Os teores de proteína bruta foram determinados pelo método semi-micro Kjeldahl descrito por Silva e Queiroz (2006). Na extração 
dos lipídios totais, foi empregado o método Bligh e Dyer (1959).

\section{RetiRADA dOS CORPOS-DE-PROVA PARA OSTESTES FÍSICO-MECÂNICOS}

Após o processamento das peles, foram utilizados 20 couros de cada espécie para obtenção dos corpos-de-prova de cada tratamento. A figura 1 mostra a retirada do corpo de provas do corpo de tilápia do Nilo. As amostras analisadas foram retiradas do couro (ABNT, 1990) no sentido longitudinal ao comprimento do peixe, próximo à região dorsal, com auxílio de um balancim e em seguida foram levados para um ambiente climatizado em torno de $23 \pm 2{ }^{\circ} \mathrm{C}$ e umidade relativa do ar de $50 \pm 5 \%$, por $48 \mathrm{~h}$ (ABNT, 2006). Foram determinadas as medidas de espessura de cada amostra (ABNT, 2005b) para os cálculos de resistência à tração e alongamento (ABNT, 1997a) e ao rasgamento progressivo (ABNT, 2005a).

Para os testes de resistência foi utilizado o dinamômetro da marca EMIC, com velocidade de afastamento entre as cargas de $100 \pm 20 \mathrm{~mm} / \mathrm{min}$. Foi utilizada uma célula de carga de $200 \mathrm{kgf}$. A calibração foi realizada pela Emic-Dcame, laboratório de calibração credenciado pela Cgcre/Inmetro sob n ${ }^{\circ}$ 197. O número do certificado de calibração da célula de carga do dinamômetro é 288/08 emitida em 16 de maio de 2008.

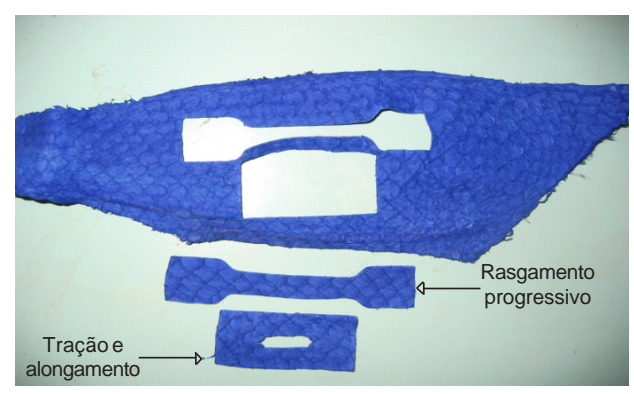

Figura 1. Retirada dos corpos de prova do couro de tilápia no sentido longitudinal. (Withdrawal of tilápia leathers specimens in the longitudinal direction).

\section{ANÁLISE FÍSICO-QUÍMICA DO COURO}

A preparação de amostras de couro para análise química seguiu as condições exigidas pelas normas (ABNT, 2001), para a determinação do óxido de cromo $\mathrm{Cr}_{2} \mathrm{O}_{3}$ seguiu-se ABNT (1999a), determinação das substâncias extraíveis com diclorometano $\left(\mathrm{CH}_{2} \mathrm{Cl}_{2}\right) \mathrm{ABNT}$ (1997b) e a determinação do $\mathrm{pHe}$ da cifra diferencial do $\mathrm{pH}$ de um extrato aquoso ABNT (1999b).

\section{DELINEAMENTO EXPERIMENTAL E ANÁLISE ESTATÍSTICA}

Foi utilizado um delineamento inteiramente casualizado com 3 tratamentos ( $\mathrm{T} 1=$ tilápia; $\mathrm{T} 2=$ pacu e T3= tambaqui). A unidade experimental para todos os ensaios foi o couro. Os resultados dos testes físicomecânicos foram submetidos à análise de variância e as médias comparadas pelo teste de Tukey, ao nível de $5 \%$ de probabilidade. Os dados foram analisados pelo programa estatístico SAEG (1997).

\section{RESULTADOSEDISCUSSÃO}

A pele do peixe apresenta um desenho de flor, que é característico de cada espécie. Esse desenho é caracterizado pelas lamélulas de proteção e inserção das escamas, formando mosaicos únicos.

O couro de tilápia apresenta um desenho de flor com lamélulas de proteção e inserção das escamas com maior definição em tamanho (espaço referente ao local onde estava a escama) e comprimento (tecido dérmico que sobrepõe a porção anterior da escama) (figura 2). Os couros de pacu e tambaqui (figura 2), por sua vez apresentam um desenho de flor mais suave, ou seja, com lamélulas de menor tamanho e abertura. Todavia, comparando essas duas peles, pode-se notar, que as lamélulas da pele de pacu são bem menores que as de tambaqui. O fato das lamélulas serem pequenas está diretamente relacionado com o tamanho da escama e o grau de inserção da mesma na pele, ou seja, quanto menor o tamanho da 


\section{ANÁLISE COMPARATIVA DAS PELES DE TILÁPIA DO NILO, PACU E TAMBAQUI}

lamélula, mais difíceis das escamas saírem da pele durante o processo de curtimento. Portanto, nas peles de tilápia, lamélulas maiores, as escamas saem com muita facilidade, apenas algumas rotações do equipamento (fulão com a solução de remolho e as peles) são suficiente para que as mesmas se soltem. Por outro lado nos pacus e tambaquis, por apresentarem lamélulas menores, principalmente referente a linha lateral, observou-se que para conseguir retirar as escamas se faz necessário realizar a etapa de caleiro por um período prolongado, de pelo menos 3 horas.

Essa dificuldade de retirada da pele é compensada, a princípio, pelo seu tamanho, normalmente os animais são abatidos acima de $1500 \mathrm{~g}$, proporcionando peles de maior área útil de aproveitamento.

\section{ANÁLISE HISTOLÓGICA DAS PELES}

A pele das três espécies (tilápia do Nilo, pacu e tambaqui) é formada por três camadas distintas: epiderme, derme e hipoderme. Todavia, as análises relatadas a seguir restringem-se a camada epidérmica e dérmica.

A epiderme da pele da tilápia do Nilo é formada por tecido epitelial pavimentoso estratificado, com subcamadas de células epiteliais. As células epiteliais da camada germinativa, observadas na pele de tilápia do Nilo são cilíndricas com núcleo oval, apoiadas na membrana basal nítida (figura 3A). A epiderme do pacu e tambaqui é mais delgada com camadas sobrepostas de célu- las epiteliais (figura 3B,C).

Segundo Pasos (2002), a epiderme varia em número de estrato celulares entre espécies e em diferentes regiões na mesma espécie. Na epiderme do pacu e tambaqui foram encontradas células mucosas, porém na do tambaqui em maior proporção. As celulas mucosas produzem mucina, uma glicoproteína formadora do muco (delgada secreção lubrificante e protetora). Em relação a essas células, segundo Hinton e Laurén (1990), o número e tamanho dessas podem variar entre as espécies e dentro de uma mesma espécie, em função do ambiente. E ainda, podem variar na diferentes áreas do corpo de um mesmo indivíduo (Whitear e Zaccone, 1984).

A derme, segunda camada da pele, é composta por duas camadas, sendo uma superficial, localizada logo abaixo à epiderme, composta por fibras finas com melanóforos e outra, no estrato mais profundo (derme compacta) com fibras colágenas dispostas paralelamente à superfície da pele, sendo que em algumas espécies, são observadas muitas fibras colágenas dispostas no sentido transversal a superfície da pele. Hawkes (1974) e Souza et al. (2003) afirmam que a organização das camadas de colágenos da derme difere de acordo com a área do corpo examinada e espécies de peixe.

Abaixo da membrana basal, no tecido conjuntivo frouxo (derme superficial), nas peles das três espécies de peixes, foi observado a presença de melanóforos, células que sintetizam melanina (figura 3). Pasos

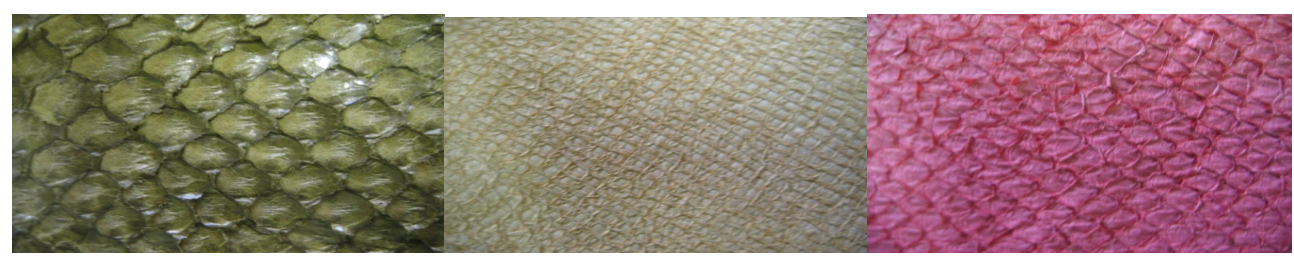

Tilápia do Nilo

Pacu

Tambaqui

Figura 2. Desenho de flor dos couros. (Leathers flower drawing). 

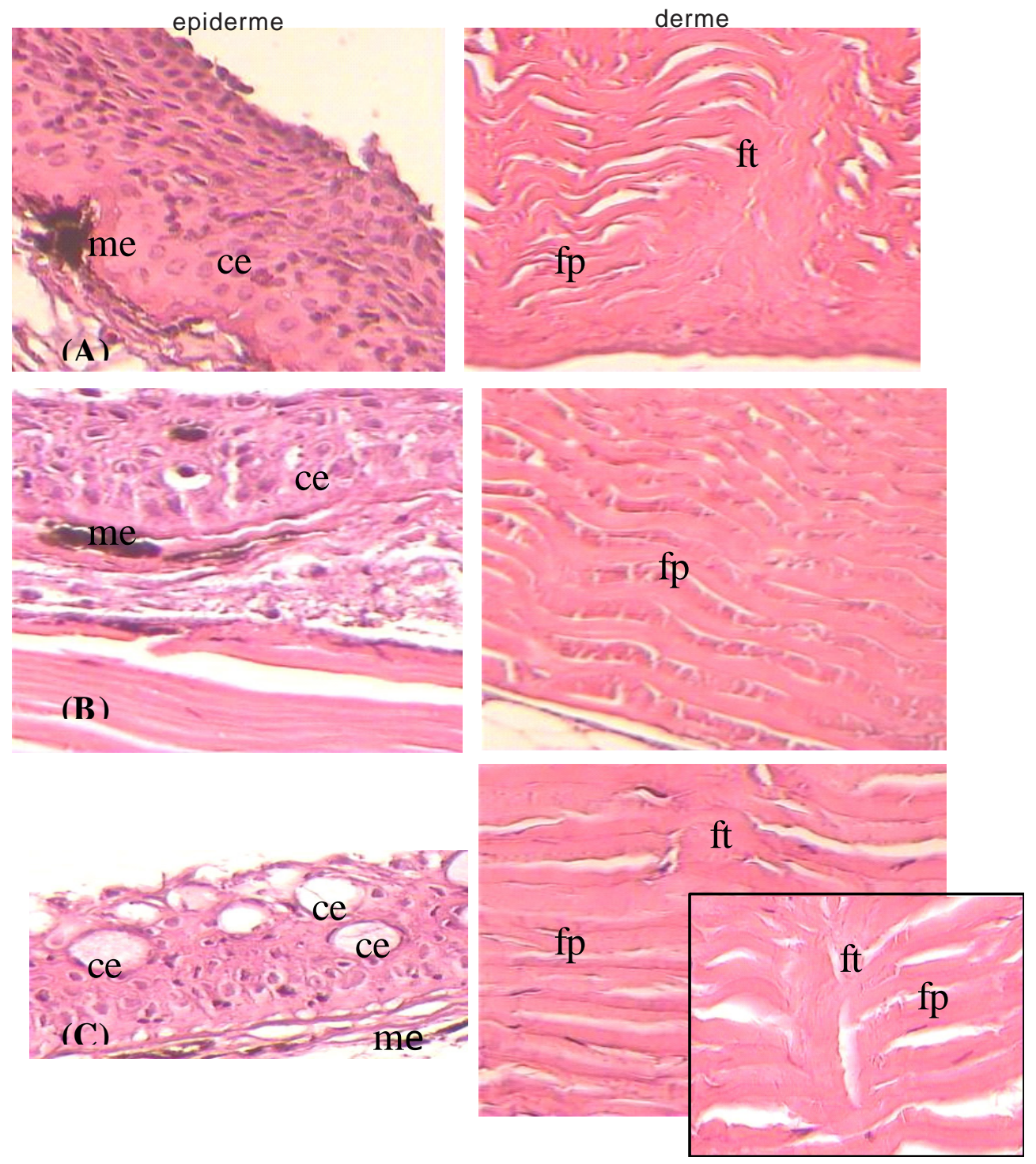

Figura 3. Fotomicrografia das peles de tilápia do Nilo (A), pacu (B) e tambaqui (C), mostrando: a epiderme a esquerda e a derme a direita. A epiderme com as células epiteliais (ce) e mucosas (cm). Melanóforos (me) entre a epiderme e derme. A derme profunda, com as fibras colágenas paralelas ( $f p)$ e transversais ( $f t)$ à epiderme. Objetiva: $20 x$. Coloração HE. (Photomicrograph of the skins of tilápia do Nilo (A), pacu (B) and tambaqui (C), showing: the epidermis to left and dermis to right. The epidermal epithelial cells $(\mathrm{ce})$ and mucosa $(\mathrm{cm})$. Melanophores (me) between the epidermis and dermis. The deep dermis, with collagen fibers parallel (fp) and transverse (ft) to the epidermis. Objective: $20 \mathrm{x}$. HE staining).

Archivos de zootecnia vol. 62, núm. 237, p. 26. 


\section{ANÁLISE COMPARATIVA DAS PELES DE TILÁPIA DO NILO, PACUE TAMBAQUI}

(2002), relata que a pele de peixe apresenta uma característica importante, sua pigmentação, esta se deve a os cromatóforos, com pigmentos de vários tipos que podem ser negros (melanóforos), como os encontrados na pele das três espécies analisadas neste trabalho. Na pele de peixes em geral, a derme consiste em uma relativa camada superior de tecido difuso, zona denominada de estrato compacto. Esta zona é rica em fibras de colágeno, as quais estão dispotas em forma paralela à flor da pele e entrecruzadas entre si em lâminas, no formato de redes entrecruzadas (Pasos, 2002). Estas citações se confirmam quando se observa a figura 3. Para pele de tilápia, a camada mais profunda da derme apresenta feixes de fibras colágenas finos, sobrepostos e cruzados no sentido transversal a superfície da pele. Nas peles de pacu e tambaqui também se observa essa característica, porém com fibras mais grossas no sentido longitudinal e transversal à superfície da pele.

\section{COMPOSIÇÃO}

A composição centesimal das peles das três espécies de peixes utilizadas consta na tabela I.

É escassa a literatura referente a composição das peles. De acordo com Hoinacki (1989), o teor de água da pele varia entre 60 e $70 \%$. Os valores observados neste estudo para as peles de tilápia do Nilo, pacu e tambaqui estão dentro dos relatados por Hoinacki (1989).

Souza (2003) relata valores de 68,20 a $70,19 \%$ de umidade, 26,59 a $28,66 \%$ de proteína bruta, 1,86 a 3,43\% de gordura e 1,32 a 2,21\% de cinzas nas peles de tilápias, em função do peso de abate (500 a $800 \mathrm{~g}$ ). Neste experimento foram observados valores muito próximos a esses para as mesmas características.

Bordignon (2010) observou teores de proteína bruta na pele da tilápia do Nilo de 18,16 e $19,57 \%$ respectivamente, para as peles conservadas nos métodos de congelamento e salga. Segundo o autor os va- lores de proteína bruta das peles de tilápia obtidos por ele, foram inferiores aos relatados na literatura, isso em função do maior teor de umidade das peles quando utilizadas para a análise de composição centesimal. As peles foram lavadas antes das análises para evita principalmente o efeito da presença do sal nas peles salgadas.

A pele é composta de maior proporção de fibras colágenas, comparada às demais proteínas fibrosas (elastina e reticultina), e é o colágeno que se combina aos agentes curtentes para transformar a pele em couro (Hoinacki, 1989). As peles de tambaqui apresentaram maior teor de proteína bruta (tabela I), sendo assim, é esperado que os couros de tambaqui apresentem uma maior resistência à tração e ao rasgamento progressivo, comparada aos demais couros analisados.

A pele de tilápia apresentou maior teor de lípideos, provavelmente isto esteja relacionado com a forma de retirada da pele do animal. Nos pacus e tambaquis as peles estão mais firmemente fixadas à musculatura, quando a pele é removida permanece na musculatura boa parte de perímisio (Contrerás-Guzmán, 1994). Portanto, os teores de lipídeos das peles podem ter variado em função do método de remoção da pele, ou seja, com o auxílio de alicate ou faca.

A quantidade de graxa presente na pele influencia no processo de curtimento. Quanto maior for o teor de graxa, maior a quantidade de tensoativos e solventes que

Tabela I. Valores médios da composição das peles in natura de três espécies de peixes. (Mean values of composition of fresh skins of three species of fish).

\begin{tabular}{lcccc}
\hline & $\begin{array}{c}\text { Umidade } \\
(\%)\end{array}$ & $\begin{array}{c}\text { PB } \\
(\%)\end{array}$ & $\begin{array}{c}\text { Lipídeos } \\
(\%)\end{array}$ & $\begin{array}{c}\text { Cinzas } \\
(\%)\end{array}$ \\
\hline Tilápia & 67,14 & 29,08 & 1,96 & 1,82 \\
Pacu & 64,20 & 32,68 & 1,77 & 1,32 \\
Tambaqui & 61,03 & 35,70 & 1,82 & 1,45 \\
\hline
\end{tabular}


devem ser utilizados, e maior o tempo das etapas que envolvem a adição de tensoativos (Souza, 2008).

$\mathrm{O}$ alto teor de gordura existente nas peles de determinados pescados, pode dificultar a penetração de substâncias químicas e curtente, que são utilizados durante o processo de curtimento, principalmente nas etapas de curtimento, recurtimento e tingimento dos couros. Necessitando desta forma da realização do desengraxe (Almeida, 1998).

Com os valores observados nas referidas peles, a etapa de desengraxe pode ser realizada na forma padrão com $100 \%$ de água, $0,5 \%$ de tensoativo por 30 minutos e repetir os mesmos percentuais por mais 30 minutos.

\section{ANÁLISE FÍSICO-MECÂNICO}

Devido à complexidade do processo de transformação da pele em couro, há a necessidade da determinação da sua resistência para utilização em vestuários, calçados, cintos, bolsas, entre outros. Todavia, não existem parâmetros específicos para couros de peixes. Portanto, nesta pesquisa foram determinadas apenas a tração e alongamento e rasgamento progressivo, retirando-se os corpos-deprova no sentido ao eixo céfalo-caudal, ou seja, no sentido longitudinal ao comprimento do corpo do animal.

Os testes de resistência à tração e ao alongamento, realizados nos couros das três espécies de peixes, constam na tabela II e a determinação do rasgamento progressivo, na tabela III.

O couro de tilápia apresentou significativamente uma menor espessura comparada ao de pacu e tambaqui, que não diferiram entre si (tabela II).

Houve diferença significativa $(\mathrm{p}<0,01)$ para a força máxima aplicada nos corpos de prova para determinação da tração e alongamento. Os valores médios obtidos foram crescentes, sendo o menor para o couro de tilápia $(81,06 \mathrm{~N})$ e o maior para o
Tabela II. Valores médios dos testes de tração e alongamento dos couros de três espécies de peixes. (Mean values of strength and stretching tests of three species of fish leathers).

\begin{tabular}{|c|c|c|c|c|}
\hline & $\begin{array}{l}\text { Espessura } \\
\text { (mm) }\end{array}$ & $\begin{array}{l}\text { Tração } \\
\left(\mathrm{N} / \mathrm{mm}^{2}\right)\end{array}$ & $\begin{array}{c}\text { Alongamento } \\
(\%)\end{array}$ & $\begin{array}{l}\text { Força } \\
\text { máxima }\end{array}$ \\
\hline & & & $52,63^{\mathrm{B}}$ & \\
\hline $\mathrm{Pac}$ & & & & $153,06^{\mathrm{B}}$ \\
\hline Tambaqui & ii $0,89^{A}$ & $29,4 \mathrm{C}$ & $66,69^{A B}$ & $224,25^{A}$ \\
\hline Teste F & $11,64^{* *}$ & $14,38^{* *}$ & $5,69^{\star *}$ & $15,26^{\star *}$ \\
\hline CV (\%) & 15,36 & 47,62 & 26,79 & 47,98 \\
\hline
\end{tabular}

${ }^{A B C}$ Letras diferentes na mesma coluna apresentam diferenças significativas estatisticamente pelo teste de Tukey $(p<0,05)$. ${ }^{* *} p<0,01$.

tambaqui (224,25 N) (tabela II).

Quando analisado a tração necessária para a ruptura do corpo de prova, observase na tabela II, que os couros de tambaqui foram significativamente superiores em resistência $\left(29,49 \mathrm{~N} / \mathrm{mm}^{2}\right)$ aos demais, que não diferiram entre si (Tilápia 11,86 N/mm² e Pacu 18,07 N/mm²).

Quanto ao alongamento, o couro de pacu apresentou maior porcentagem $(72,50 \%)$, comparado ao de tilápia, apesar de não ter

Tabela III. Valores médios dos testes de rasgamento progressivo dos couros de três espécies de peixes. (Mean values of progressive tearing tests of three species of fish leathers).

\begin{tabular}{lccc}
\hline & $\begin{array}{c}\text { Espessura } \\
(\mathrm{mm})\end{array}$ & $\begin{array}{c}\text { Rasgamento } \\
\text { progressivo }^{1}\end{array}$ & $\begin{array}{c}\text { Força } \\
\text { máxima }^{2}\end{array}$ \\
\hline Tilápia & $0,65^{\mathrm{B}}$ & $40,18^{\mathrm{C}}$ & $27,31^{\mathrm{C}}$ \\
Pacu & $0,85^{\mathrm{A}}$ & $63,72^{\mathrm{B}}$ & $53,94^{\mathrm{B}}$ \\
Tambaqui & $0,87^{\mathrm{A}}$ & $80,01^{\mathrm{A}}$ & $71,38^{\mathrm{A}}$ \\
Teste F & $15,97^{\star *}$ & $27,05^{\star *}$ & $24,36^{* *}$ \\
CV (\%) & 15,32 & 25,12 & 35,35
\end{tabular}

${ }^{1} \mathrm{~N} / \mathrm{mm} ;{ }^{2} \mathrm{~N}$.

${ }^{A B C}$ Letras diferentes na mesma coluna apresentam diferenças significativas estatisticamente pelo teste de Tukey $(p<0,05) .{ }^{* *} p<0,01$. 


\section{ANÁLISE COMPARATIVA DAS PELES DE TILÁPIA DO NILO, PACU E TAMBAQUI}

diferido significativamente do couro de tambaqui $(66,69 \%)$. Não houve diferença significativa entre os resultados de alongamento dos couros de tilápia e tambaqui (tabela II).

A espessura das amostras utilizadas no ensaio de rasgamento progressivo dos couros (tabela III), seguiu o mesmo padrão de resposta obtido no ensaio de tração e alongamento, sendo o couro de tilápia o de menor e o de tambaqui o de maior espessura. A determinação do rasgamento progressivo e a força aplicada neste segundo teste apresentaram diferença significativa entre as espécies, sendo que os couros de tilápia apresentaram os menores valores e o tambaqui os maiores, conforme mostra a tabela III.

Os resultados mostraram que os couros de tambaqui apresentaram maior resistência à tração, rasgamento progressivo e as forças máximas aplicadas nestes testes. O couro de tilápia apresentou menor elasticidade comparado aos demais couros, apesar de não ter diferido da elasticidade do couro de tambaqui.

De acordo com Souza e Silva (2005), peles de tilápia do Nilo, curtidas com sais de cromo e recurtidas com tanino vegetal combinado com sintético, apresentaram uma resistência a tração de $11,85 \mathrm{~N} / \mathrm{mm}$, rasgamento progressivo de $35,11 \mathrm{~N} / \mathrm{mm}$ e alongamento de 45,67\%. Os valores de rasgamento e alongamento, obtidos pelos autores, foram inferiores aos obtidos neste experimento, porém o resultado da tração foi semelhante.

Souza et al. (2003) analisando couros de pacu, com espessura variando de 0,73 a 0,88 mm, obtiveram valores de tração de 5,93 N/ $\mathrm{mm}^{2}$ e $13,81 \mathrm{~N} / \mathrm{mm}^{2}$, alongamento de 52,20 e $76,98 \%$ e para o rasgamento progressivo de $15,66 \mathrm{~N} / \mathrm{mm}$ e $13,85 \mathrm{~N} / \mathrm{mm}$, respectivamente para os sentidos longitudinal e transversal. Neste trabalho observou-se valores de tração superiores aos encontrados pelos autores.

Rocha (2007), analisando a pele de tambaqui submetida ao curtimento com tanino vegetal e sais de cromo, obteve 13,86 $\mathrm{N} / \mathrm{mm}^{2}$ e $8,39 \mathrm{~N} / \mathrm{mm}^{2}$ para o teste de tração, $55,64 \%$ e $34,64 \%$ para alongamento e 34,85 e $22,64 \mathrm{~N} / \mathrm{mm}$ para rasgamento progressivo, respectivamente. Comparando com os referidos autores, os valores obtidos neste experimento foram superiores nas três espécies analisadas.

Pelo fato de ser difícil encontrar literatura referenciando o padrão de resistência de couro de peixes para a aplicação na confecção de vestuários e calçados, tomouse como parâmetro, os valores referência mais encontrados para couro bovino. Dessa forma, apenas os couros de tambaqui curtidos pela técnica já mencionada, poderiam ser destinados à confecção de vestuários. Pois, de acordo com Vademécum (2004), os valores referência para couros de bovinos curtidos ao cromo para vestuário, independentemente do recurtimento, deve ser de, no máximo, $60 \%$ para o alongamento na ruptura, no mínimo de $25 \mathrm{~N} / \mathrm{mm}^{2}$ de resistência à tração ou tensão e no mínimo $35 \mathrm{~N} / \mathrm{mm}$ para a resistência de rasgamento progressivo.

De acordo com Gerhard (1998), as exigências de qualidade para couros para luvas curtidos com sais de cromo devem ser de no mínimo $200 \mathrm{~N} / \mathrm{cm}^{2}$ para couros de cabras e $100 \mathrm{~N} / \mathrm{cm}^{2}$ para couros de ovelhas e alongamento até a ruptura de no mínimo $50 \%$. A espessura recomendada para essa finalidade, segundo o mesmo autor é de 0,6 a 1,2 $\mathrm{mm}$ de espessura e para vestimenta é de 0,6 a 1,0 mm. Os couros curtidos neste experimento apresentam a espessura dentro do recomendado para confecção de luvas e vestimentas.

\section{ANÁLISE FÍSICO-QUÍMICO}

O resultado obtido de óxido de cromo, nos couros de tilápia do Nilo, pacu e tambaqui foram de $3,5,3,6$ e $3,6 \%$, respectivamente. O óxido de cromo está relacionado com a proporção do curtente fixado às fibras colágenas. De acordo, com Hoinacki (1989), o valor mínimo de óxido de cromo no couro 
semi-acabado deve ser de 3,0\%. Todavia, Vademécum (2004) relata que o valor de óxido de cromo no couro deve estar acima de $2,5 \%$.

O valor obtido neste experimento significa que os couros apresentaram capacidade de suportar elevadas temperaturas, sem retrair-se, ou seja, não ocorre a retração das fibras colágenas quando realizado o teste de fervura ou retração durante o processo de curtimento.

As substâncias solúveis em diclorometano variaram de 11,1 a $12,8 \%$ entre as amostras dos couros analisados das três espécies. Essa análise refere-se às substâncias que são extraíveis da amostra pelo solvente. Essa análise indica o conteúdo de óleos e graxas no couro. O Vademécum BASF (2004) relata que os valores devem estar no máximo entre 16 a $18 \%$ para o couro poder ser utilizado em vestuário.

No engraxe, as fibras colágenas devem ser recobertas pelo óleo para proporcionar um melhor tato e resistência ao rasgamento progressivo, umectabilidade com água, impermeabilidade à água e permeabilidade ao ar e vapor d'água, pelo efeito de lubrificação das fibras, evitando-se a aglutinação das mesmas (Hoinacki, 1989; Gutterres, 2001).

$\mathrm{O} \mathrm{pH}$ final do couro normalmente apresenta-se ácido, para proporcionar uma melhor fixação dos recurtentes, corantes e óleos. O pH do extrato aquoso do couro moído é determinado pelo potenciômetro e mede a concentração iônica da solução.

Neste experimento o valor do $\mathrm{pH}$ variou de 3,5 a 3,7 e a cifra diferencial foi de 0,4 . Segundo Jacinto (1996), a acidez excessiva

\section{BIBLIOGRAFIA}

ABNT. 1990. NBR 11035: Corte de corpos-deprova em couro. Associação Brasileira de Normas Técnicas. Rio de Janeiro.

ABNT. 1997a. NBR 11041: couros - determinação da resistência à tração e alongamento. Associação Brasileira de Normas Técnicas. Rio provoca a degradação da cadeia protéica pela hidrólise ácida, diminuindo a resistência do couro. Hoinacki (1989), relata que o valor mínimo de $\mathrm{pH}$ no couro semi-acabado deve ser de 3,5 e a cifra diferencial no máximo 0,7. Os valores obtidos para as três espécies estão dentro dos recomendados pelo autor.

Analisando em conjunto a estrutura histológica, composição centesimal, físicomecânico e físico-químico, das peles das três espécies, pode-se concluir que os couros que apresentaram maior resistência a tração e rasgamento foi o de tambaqui. Como as peles foram curtidas pela mesma técnica (todas as peles dentro do mesmo fulão), o que pode ter interferido nos resultados, é a arquitetura histológica das peles. Pode-se observar que nas peles de tambaqui, as fibras colágenas eram mais espessas, paralelas, porém, com grandes feixes de fibras colágenas dispostos no sentido transversal da pele. Com isto, a estruturação da derme proporcionou essa superior resistência. Quanto aos testes físico-químicos, os resultados foram semelhantes para os couros das três espécies.

Quanto à espessura do couro, pode ser observado que os couros de tambaqui e pacu foram significativamente semelhantes, portanto, se a espessura estivesse interferindo nesses resultados de resistência, os couros dessas duas espécies teriam, também a mesma resistência.

Pode-se concluir que apenas os couros de tambaqui curtidos pela técnica já mencionada, poderiam ser destinados à confecção de vestuários, porém couros das 3 espécies apresentam a espessura dentro do recomendado para confecção de luvas e vestimentas.

de Janeiro. pp. 1-5.

ABNT. 1997b. NBR 11030: couro - determinação de substâncias extraíveis com diclorometano $\left(\mathrm{CH}_{2} \mathrm{Cl}_{2}\right)$. Associação Brasileira de Normas Técnicas. Rio de Janeiro. pp. 1-3.

ABNT. 1999a. NBR 11054: couros - determinação 


\section{ANÁLISE COMPARATIVA DAS PELES DE TILÁPIA DO NILO, PACUE TAMBAQUI}

de óxido crômico $\left(\mathrm{Cr}_{2} \mathrm{O}_{3}\right)$. Associação Brasileira de Normas Técnicas. Rio de Janeiro. pp. 1-5.

ABNT. 1999b. NBR 11057: couro - determinação do $\mathrm{pH}$ e da cifra diferencial. Associação Brasileira de Normas Técnicas. Rio de Janeiro. pp. 1-3.

ABNT. 2001. NBR 11034: couro - preparação de amostras de couro para análise química. Associação Brasileira de Normas Técnicas. Rio de Janeiro. pp. 1-2

ABNT. 2005a. NBR 11055: couro: determinação da força de rasgamento progressivo. Associação Brasileira de Normas Técnicas. Rio de Janeiro. pp. 1-2.

ABNT. 2005b. NBR 11052: determinação da espessura. Associação Brasileira de Normas Técnicas. Rio de Janeiro. pp. 1-2.

ABNT. 2006. NBR 10455: climatização de materiais usados na fabricação de calçados e correlatos. Associação Brasileira de Normas Técnicas. Rio de Janeiro. pp. 1-2.

Almeida, R.R. 1998. A pele de peixe tem resistência e flexibilidade? Revista do Couro, 127: 49-53.

AOAC. 1995. Oficial methods of analysis.16 edição. Association of Official Analytical Chemists. Arlington. pp. 1-30.

Bligh, E.G. and Dyer, W.J. 1959. A rapid method of total lipid extraction and purification. Can $J$ Biochem Physiol, 37: 911-917.

Bordignon, A.C. 2010. Caracterização da pele e da gelatina extraída de peles congeladas e salgadas de tilápia do Nilo (Oreochromis niloticus). Dissertação (Mestrado em Zootecnia). Universidade Estadual de Maringá. Maringá. 113 pp.

Contreras-Guzmán, E.S. 1994. Bioquímica de pescados e derivados. Ed. FUNEP. Jaboticabal. 409 pp.

Gerhard, J. 1998. Posibles fallas en el cuero y en su producción - conceptos, causas, consecuencias, remedios y tipos de cueros. Ed. Partner Rübelmann Gmbh. Lampertheim. 378 pp.

Gutterres, M. Distribuição, deposição e interação química de substâncias de engraxe no couro. 2001. Congresso da Federação Latino-Americana das Associações dos Químicos e Técnicos da Indústria do Couro, 15. Anais... Salvador. pp. 108-119.

Hawkes, J.W. 1974. The structure of fish skin. I General organization. Cell Tissue Res, 149: 147-158.

Hinton, D.E. and Laurén, D.J. 1990. Integrative histopathological approaches to detecting effects of environmental stressors on fishes. American Fisheries Society Symposium, 8:5166. London.

Hoinacki, E. 1989. Peles e couros: origens, defeitos e industrialização. $2^{a}$ edição. Ed. Henrique d'Ávila Bertaso. Porto Alegre.

Jacinto, M.A.C. 1996. Características anátomoestruturais da pele e do couro de ovinos lanados e deslanados. Dissertação (Mestrado em Zootecnia). UNESP. Jaboticabal. $92 \mathrm{pp}$.

Martins, C.V.B.; Oliveira, D.P.; Martins, R.S.; Hermes, C.A.; Oliveira, L.G.; Vaz, S.K.; Minozzo, M.G.; Cunha, M. e Zacarkin, C.E. 2001. Avaliação da piscicultura na região oeste do estado do Paraná. Bol Inst Pesca, 27: 77-84.

Pasos, L.A.P. 2002. Piel de pescado. http:// www.cueronet.com/exoticas/pescado.htm. (21/09/2008).

Rocha, M.P.S.S. 2007. Curtimento de peles de tambaqui (Colossoma macropomum Cuvier 1888) e pirarara (Phractocephalus hemioliopteros, Bloch \& Schneir 1801) com curtente sintéticos e com curtentes naturais da Amazônica. Universidade Federal do Amazonas. Instituto Nacional de Pesquisas da Amazônia. Dissertação (Mestrado em Biologia Tropical e Recursos Naturais Agricultura no Trópico Úmido). Universidade Federal do Amazonas. Manaus. $60 \mathrm{pp}$.

SAEG. 1997. Sistemas de Análises Estatísticas e Genéticas. Versão 7.1. Universidade federal de Viçosa-UFV. Viçosa. 150 pp.

Silva, D.J. e Queiroz, A.C. 2006. Análise de alimentos: Métodos químicos e biológicos. 3aㅡ edição. Ed. UFV-Universidade Federal de Viçosa. Viçosa. 235 pp.

Souza, M.L.R. 2003. Processamento do filé e da pele da tilápia do Nilo (Oreochromis niloticus): Aspectos tecnológicos, composição centesimal, rendimento, vida útil do filé defumado e testes de resistência da pele curtida. Tese (Doutorado em Aqüicultura). UNESP. Jaboticabal. 169 pp.

Souza, M.L.R. 2008. Tecnologia para processamento das peles de peixe. $1^{\underline{a}}$ edição. Ed. Eduem. Maringá. 59 pp.

Souza, M.L.R.; Cucatti, T.; Andrade, M.B.; Godoy, L.C.; Tozzi, M.A.C.; Cavallieri, R.F.; Franco, N.P. e Silva, L.O. 2004. Diferentes técnicas de recurtimento em peles de tilápia-do-Nilo

Archivos de zootecnia vol. 62, núm. 237, p. 31. 


\section{FRANCO, FRANCO, GASPARINO, DORADO, PRADO E VESCO}

(Oreochromis niloticus): qualidade de resistência. Ensaios Cienc, 8: 195-202.

Souza, M.L.R.; Ganeco, L.N.; Nakaghi, L.S.O.; Faria, R.H.S.; Wagner, P.M.; Poyh, J.A. e Ferreira, I.C. 2003. Histologia da pele do pacu (Piaractus mesopotamicus) e testes de resistência do couro. Acta Sci Anim Sci, 25: 37-44.

Souza, M.L.R. e Silva, O.L. 2005. Efeito de técnicas de recurtimento sobre a resistência feito do couro da tilápia do Nilo (Oreochromis niloticus
L.). Acta Sci Anim Sci, 27: 535-540.

Vademécum BASF. 2004. Para el técnico em curtición. $3^{a}$ edição. Ed. Basf. Ludwigshanfen. Vaz, M.M.; Barbosa, N.D.C. e Torquato, V.C. 2000. Guia llustrado de peixes da bacia do Rio Grande. Ed. Cemig/Cetec. Belo Horizonte. 144 pp.

Whitear, M. and Zaccone, G. 1984. Fine structure and histochemistry of club cells in the skin of three species of eel. $Z$ mikrosk Anat Forsc, 98: 481-501. 